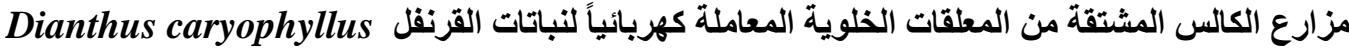

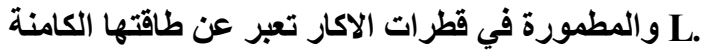

\title{
Callus Cultures derived from electrotreated cell suspension of Dianthus caryophyllus L. embedded in agar drops express their totipotency
}

$$
\text { جميلة هزاع رشيد }
$$$$
\text { سهلة محمد زيدان }
$$

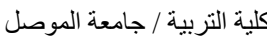

\section{المستخلص}

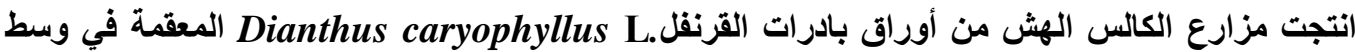
الاستحداث MS الصلب المدعم بإضافات 0.5 ملفم/لتر -1

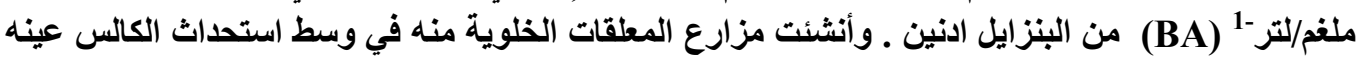

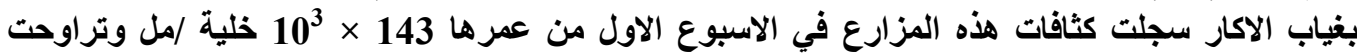

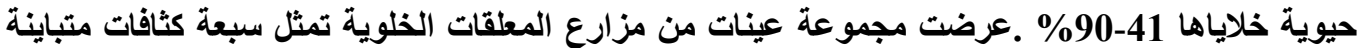

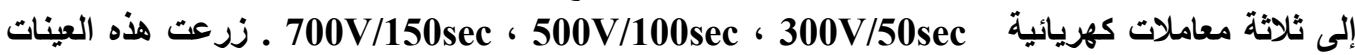
بطمرها في قطرات الاكار بأعتماد المزرعة الصلبة ـ السائلة ـ ويرهنت مزارعات الكارئات الكالس المشتقة من البادئات

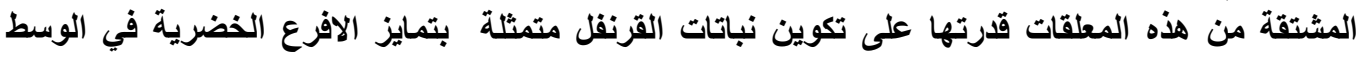

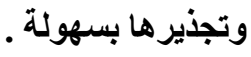

Abstract

Callus cultures were produced from leaf, excised from axenic carnation, Dianthus caryophyllus L. seedling, on agar-solidified MS medium supplemented with $0.5 \mathrm{mgl}^{-1}$ of 2,4-D and $0.1 \mathrm{mgl}^{-1}$ of BA. Cell suspension was initiated in liquid MS medium containing the above growth regulators. This suspension reported the density of $143 \times 10^{3}$ cell $/ \mathrm{ml}$ and its viability was ranged between 41-90\%. Samples of cell suspension represents seven different densities were exposed to three electrotreatment $300 \mathrm{v} / 50 \mathrm{msec}, 500 \mathrm{v} / 100 \mathrm{msec}$. and $700 \mathrm{v} / 150$ msec. These electrotreated samples were cultured by embedding in to agar drops in solid- liquid cultures. Callus derived from cell suspension expressed their totipotency forming carnation plants.

المقدمة

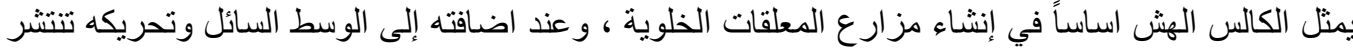

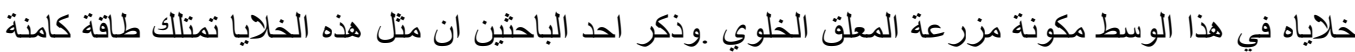

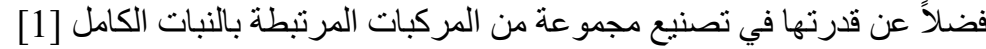

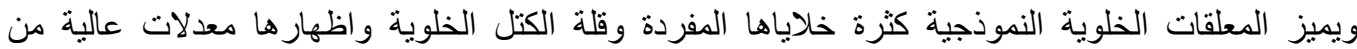

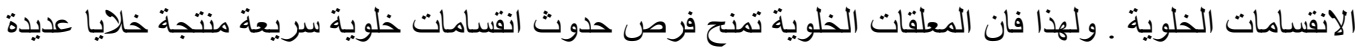

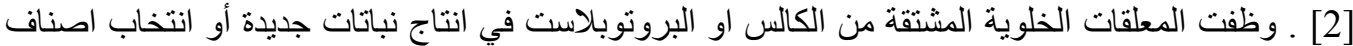

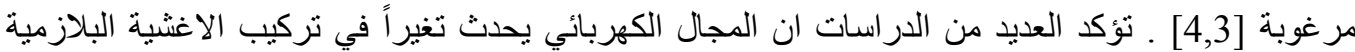

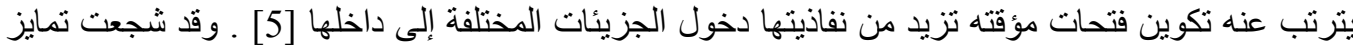

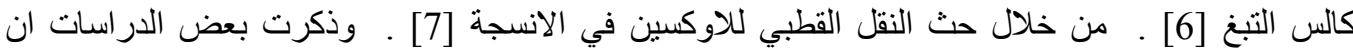

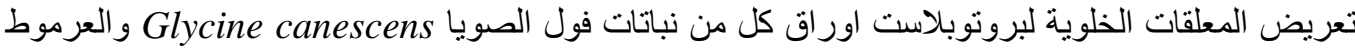

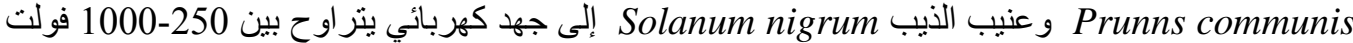

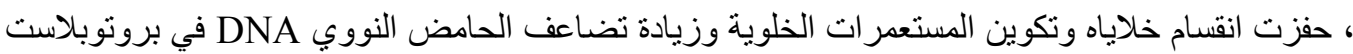
عنيب الذيب Solanum dulcamora عند تعريضه لفولتيات تر اوحت بين 250-1250 فولت [8] ـ ودعمها فيات 
Solanum nigrum بناء البروتينات ـ ووجدت دراسات اخرى ان هذه المعاملة شجعت نمو كالس عنيب الذيب إنيات

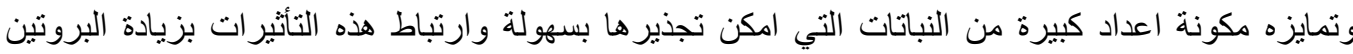

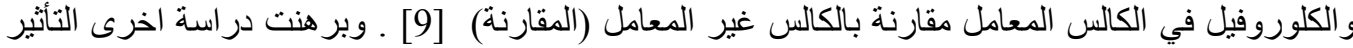

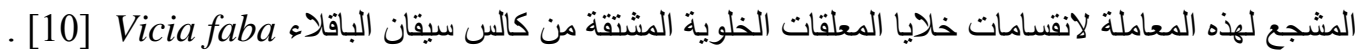

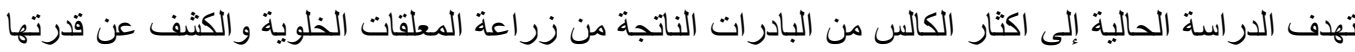

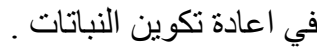

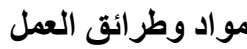

انتاج البادرات المعقمة العمل عقدت بذور القرنفل Dianthus caryophyllus L. (صنف محلي) سطحياً باستخدام هايبوكلورايت

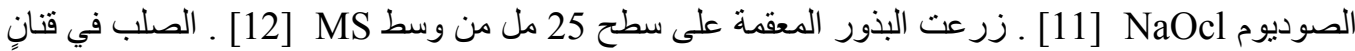

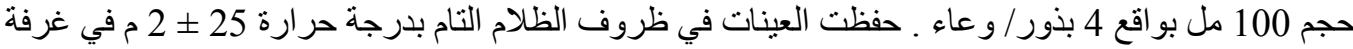

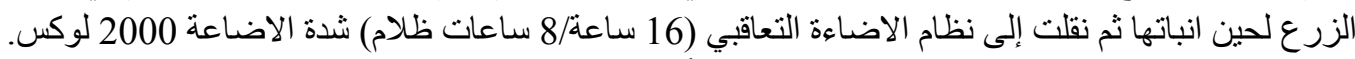

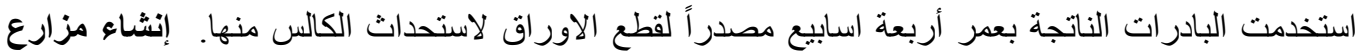

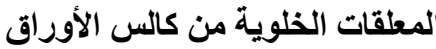

وضع غر ام واحد من كالس الاور اق الهش النامي في الوسط [11] ـ بعمر 25 يوماً في دوارق زجاجية تحتوي 50 مل من وسط الاستحداث المشار اليه بحالته السائلة .

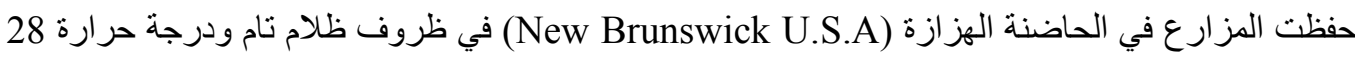

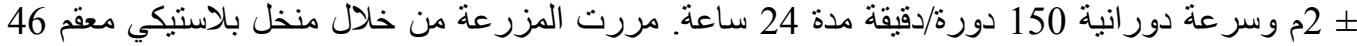
مايكروميتر (PGMG.Nott Univ., U.K.) و واستقبلت الخلايا المفردة واكمل حجمها إلى 50 مل بإضافة

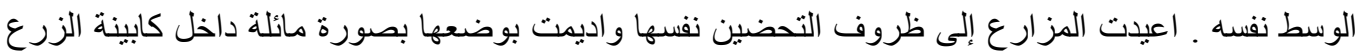

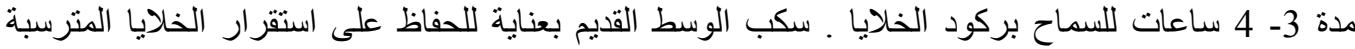

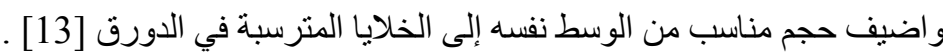
تقدير حيوية خلايا المعلقات الخلوية

اتبعت الطريقة المعتمدة في تقدير حيوية البرونوبلاست باستخدام صبغة Evan blue [14] ـ أخذ 0.1

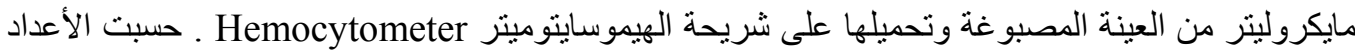

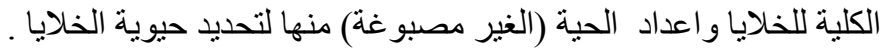
تعريض المعلقات الخلوية المشتقة من كالس الاوراق للمعاملة الكهربائية

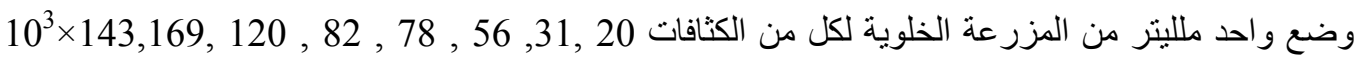

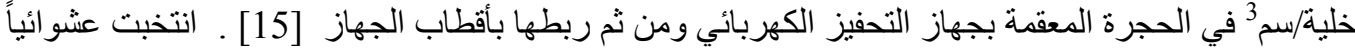

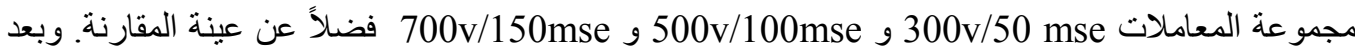

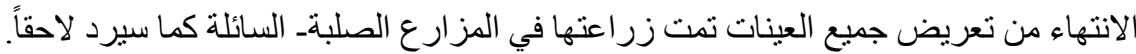

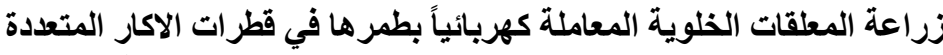

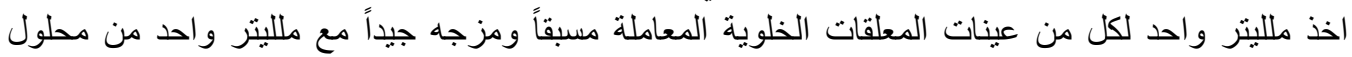

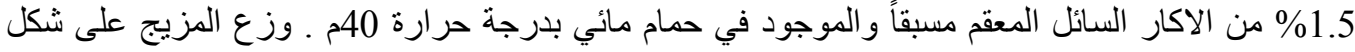

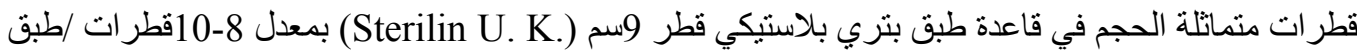

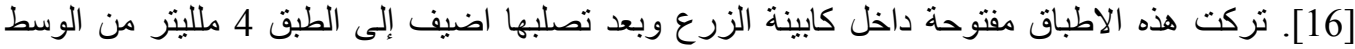

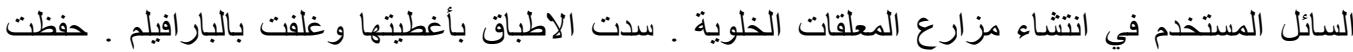

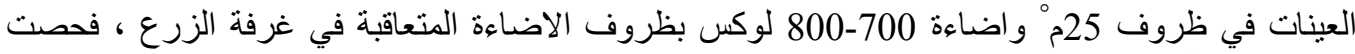

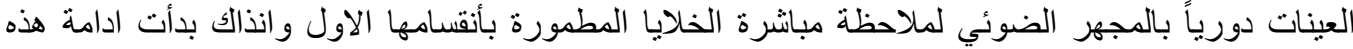

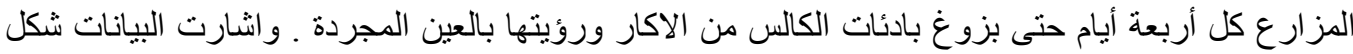

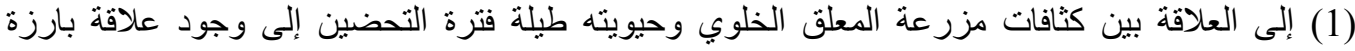


إزالة ونقل البادئات المتكونة في القطرات وتكوين مزارع الكالس

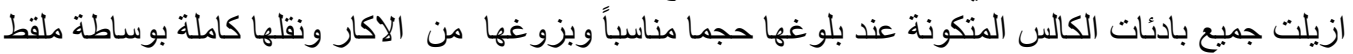

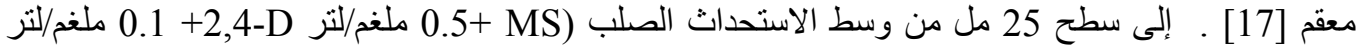

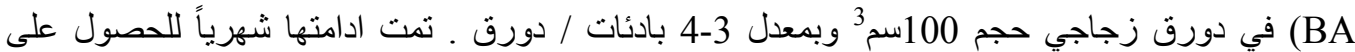
مز مزارع من الكالس.

تمايز كالس المعلقات الخلوية المعامل كهربائياً

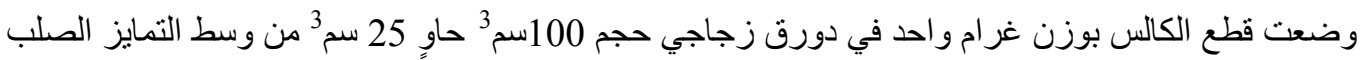
0.06 + MS

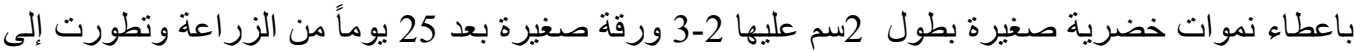

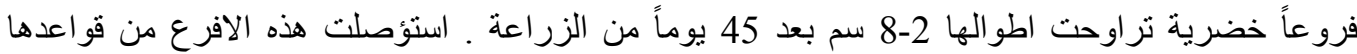
بوساطة مشرط حاد معقم ونقل كل فرع و غرست قاعدته بصورة قائمة في وسط التجذير MS الصناعة الصلب الخالي من

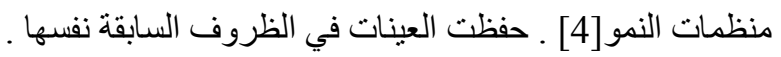
النتائج تكوين مزارع كالس الاوراق عبرت قطع الاوراق المستأصلة من بادرات القرنفل . Dianthus caryophyllus L. المعقدة بعمر أربعة

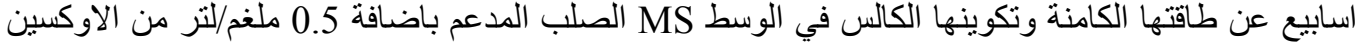

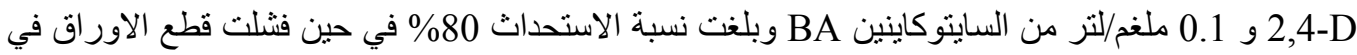

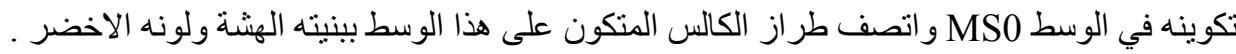
توظيف الكالس الهش في تكوين المعلقات الخلوية

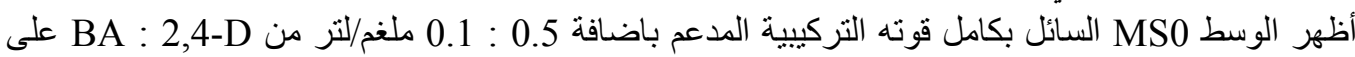

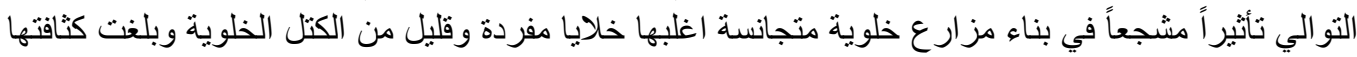

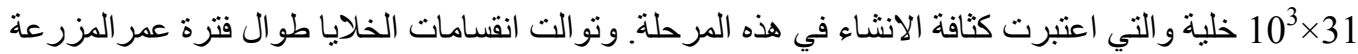

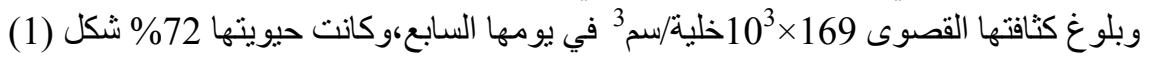

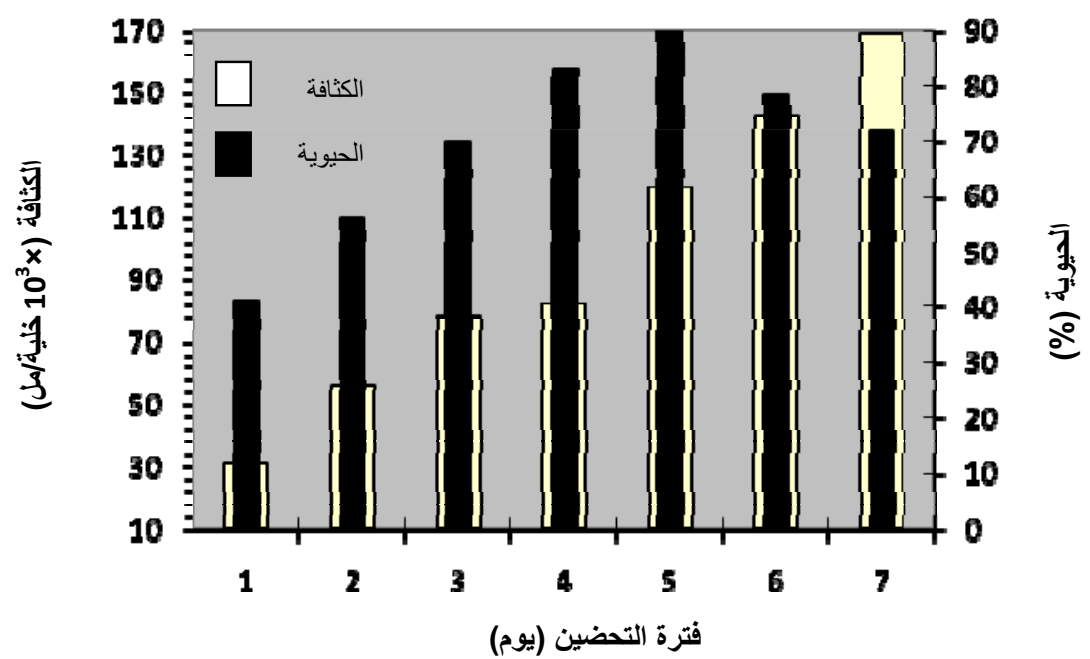

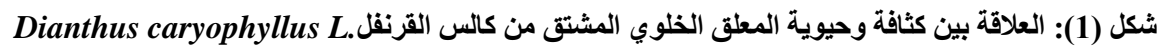

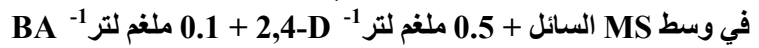

زراعة المعلقات الخلوية غير المعرضة والمعرضة للمعاملة الكهربائية بطمرها في قطرات الاكار المتعددة

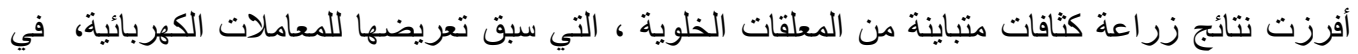

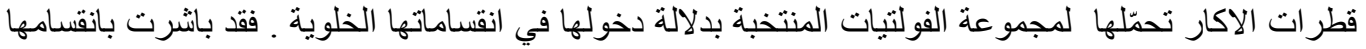

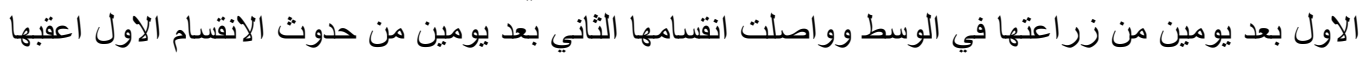


ظهور المر احل ثلاثية ورباعية للخلية بعد 7 أيام من الزراعة. و عبرت هذه الخلايا عن طاقتها باستمرار

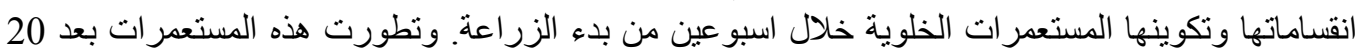

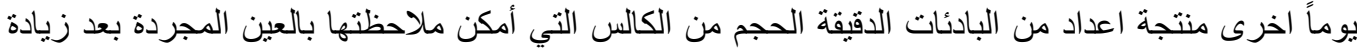

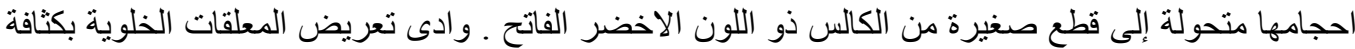

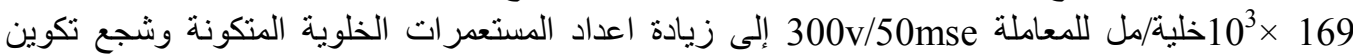

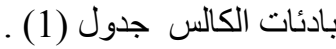

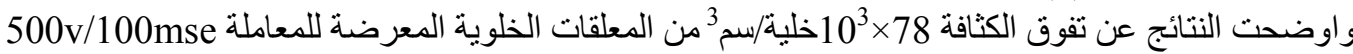
عن بقية المعاملات في الأعداد الكلية للمستعمر ات الخلوية وبادئات الكالس المتكونة جدول(2).

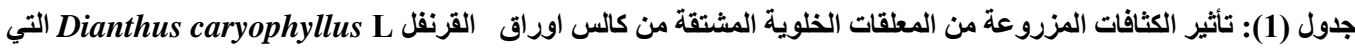
سبق تعريضها للمعاملة 300v/50mse في تكوين المستعمرات الخلوية وبادئات الكالس في قطرات الكات الاكار

\begin{tabular}{|c|c|c|c|c|c|}
\hline \multirow{2}{*}{ الكالس } & \multicolumn{4}{|c|}{ الأعداد الكلية } & \multirow{3}{*}{ كثافة المعلق } \\
\hline & ليائيات & للاقط ات & المستعمد ات & القط ات & \\
\hline (\%) & الكالس & المستحدثة & المتكونة & المزروعة & \\
\hline 60 & 88 & 9 & 90 & 15 & 20* \\
\hline 72 & 96 & 18 & 117 & 25 & 31 \\
\hline 79 & 102 & 11 & 122 & 14 & 56 \\
\hline 72 & 112 & 13 & 143 & 18 & 78 \\
\hline 63 & 150 & 10 & 178 & 16 & 82 \\
\hline 80 & 198 & 12 & 260 & 15 & 120 \\
\hline 71 & 153 & 12 & 210 & 17 & 143 \\
\hline 63 & 162 & 10 & 320 & 16 & 169 \\
\hline
\end{tabular}

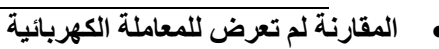

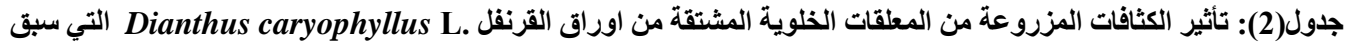

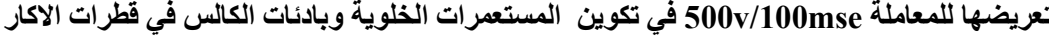

\begin{tabular}{|c|c|c|c|c|c|}
\hline & \multicolumn{4}{|c|}{ الأعداد الكلية } & كثافة المعلق \\
\hline الكالس & & للقطرات. & & & الخلوي \\
\hline (\%) & الكالس & اللكالس & المتكونة & المزروعة & 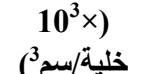 \\
\hline
\end{tabular}

\begin{tabular}{cccccc}
67 & 66 & 8 & 74 & 12 & $20 *$ \\
79 & 163 & 11 & 275 & 14 & 31 \\
72 & 182 & 13 & 322 & 18 & 56 \\
90 & 299 & 10 & 408 & 11 & 78 \\
71 & 158 & 10 & 160 & 14 & 82 \\
69 & 122 & 18 & 175 & 26 & 120 \\
68 & 108 & 13 & 257 & 19 & 143 \\
67 & 166 & 10 & 178 & 15 & 169 \\
\hline
\end{tabular}

وتظهر نتائج الجدول نفسه ان الكثافتين بالكثافات الأخرى مع تفوقها في اعداد البادئات المتكونة فضلاً من اعدادها التي تطورت بعد 28 يوماً من التها

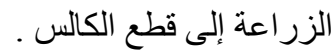

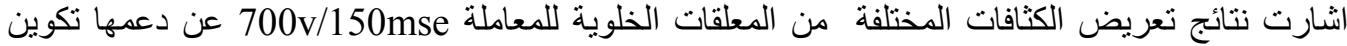
بادئات الكالس في قطرات الاكار جدول (3) وتفوقت الكثافة 78 × $10^{3}$ خلية/سمة في في اعداد المستعمرات

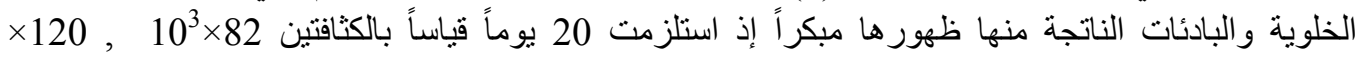




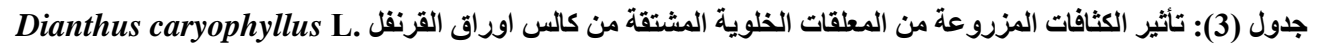

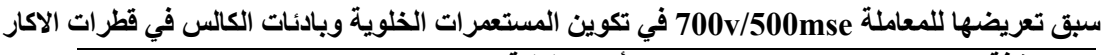

\begin{tabular}{|c|c|c|c|c|c|}
\hline & \multicolumn{4}{|c|}{ الأعداد الكلية } & كثافة \\
\hline $\begin{array}{l}\text { الكالسئات } \\
\text { (\%) }\end{array}$ & البادئات & للالمطرات & المستعمرنة المتكو & المزروعة القطرات & خلية الخلوي \\
\hline 57 & 77 & 8 & 97 & 14 & $20 *$ \\
\hline 67 & 110 & 8 & 140 & 12 & 31 \\
\hline 75 & 113 & 18 & 169 & 24 & 56 \\
\hline 82 & 150 & 18 & 327 & 22 & 78 \\
\hline 73 & 198 & 11 & 300 & 15 & 82 \\
\hline 77 & 212 & 17 & 320 & 22 & 120 \\
\hline 67 & 88 & 12 & 185 & 18 & 143 \\
\hline 71 & 75 & 10 & 120 & 14 & 169 \\
\hline
\end{tabular}

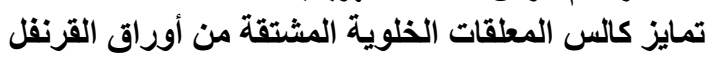

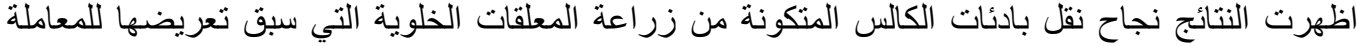

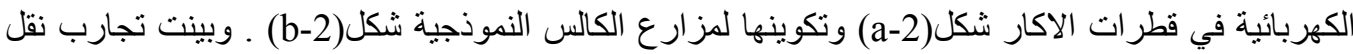
قطع الكالس من مزرعة هذا الكالس إلى وسط التمايز الصلب 0.06 + MS ملغم/لتز

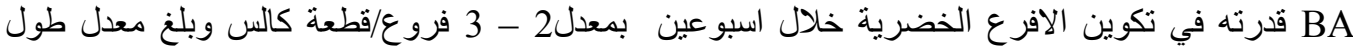

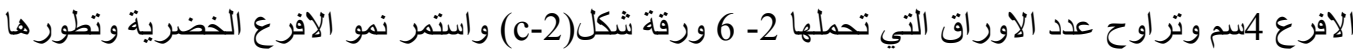

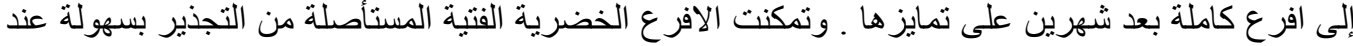

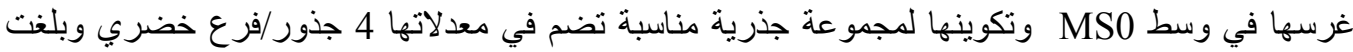

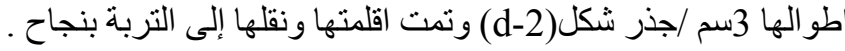

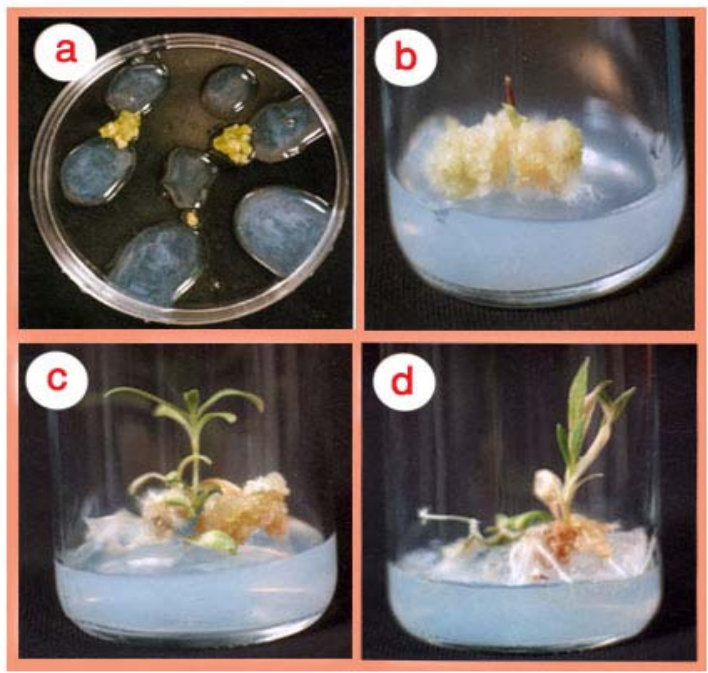

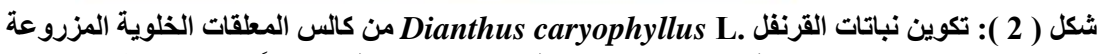

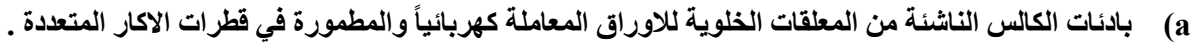

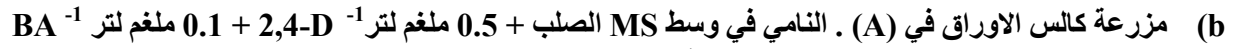
تمايز كالس المعلقات الخلوية المعاملة كهربائياً إلى افرع خضرية في وسط 
ان مزارع المعلقات الخلوية في هذه الدراسة وفّرت نظاماً بيولوجياً مناسباً لمتابعة سلوك الخلايا في انقساماتها

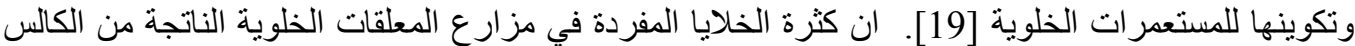

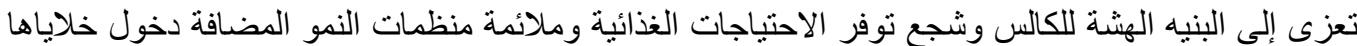

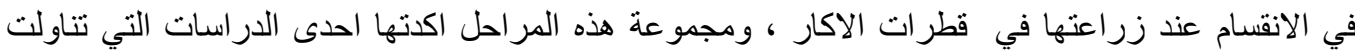

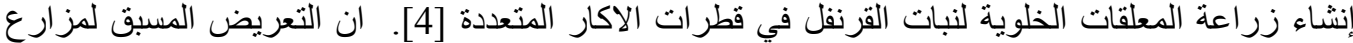

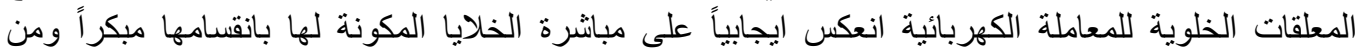
المحتمل ان يفسر هذا التأثثر الايجابي إلى تتجيع بناء الحامض النووي DNA وكذللك بناء البروتين في هذه

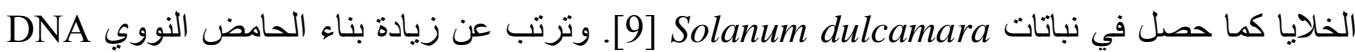
زيادة في معدلات الانقسامات التي نعاني منها الخلايا كما في نبات

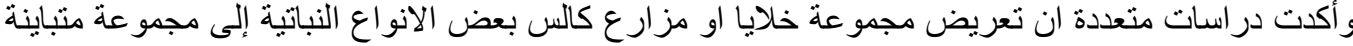

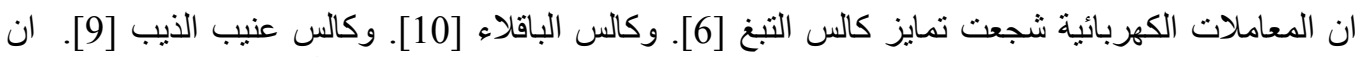

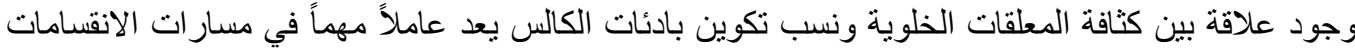

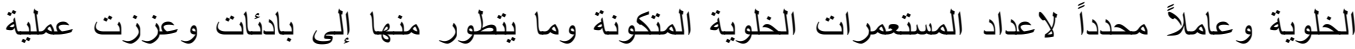

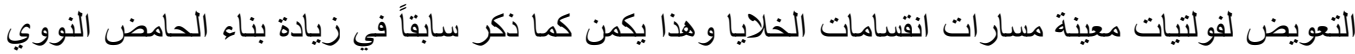

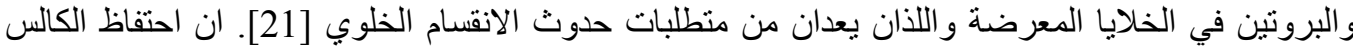

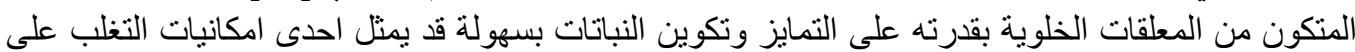

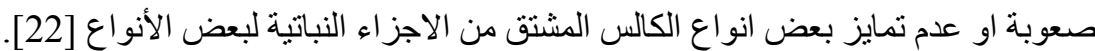

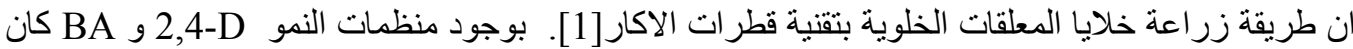

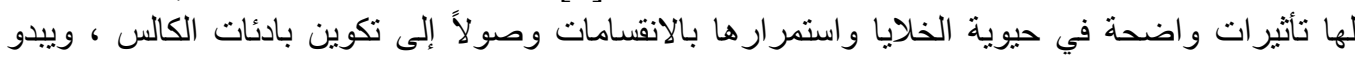

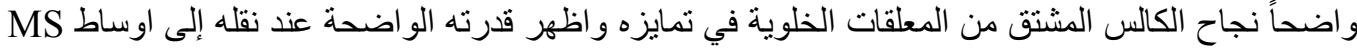

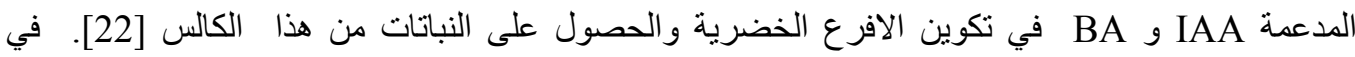

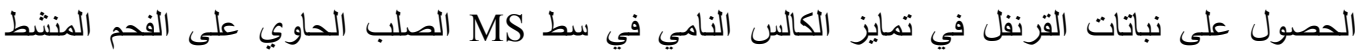

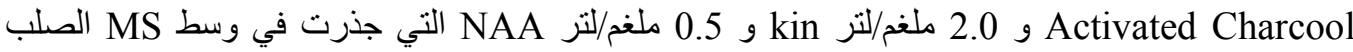

$$
\text { المحتوي على } 0.5 \text { - } 0.2 \text { ملغم/لتر IBA }
$$

1. Dixon, R. A. (1985). Plant Cell Culture Apractical Approach. IRL. Press. Oxford U. K

2. Engvild, K. C. (1972). Callus and cell suspension culture of Carnation. Physiol. Plant. 26: 62-66.

3. Larkin, P. J. and Scowcroft, W. R. (1981). Somaclonal varetion anovel source of variability from cell culture for plant improvement. Theor. Appl. Genet. 60: 197214.

4. Thakur, M., Sharma, D. R. and Sharma, S. K. (2002). In vitro selection and regeneration of carnation (Dianthus caryophyllus L.) plants resistant to culture filtrate of Fusarium Oxysporum dianthi. Plant Cell Rep. 20: 825- 828.

5. Joersbo, M. and Brunstedt, J. (1991). Electroporation: Mechanism and transient expression, stable transformation and biological effects in plant protoplasts. Physiol. Plant. 81:256-264.

6. AL-Mallah, M. K. (1993). Electroporation enhanced plant regeneration from the callus of Nicotiana tabacum. $2^{\text {nd }}$ Arab. Conf. Modern. Biotech. 24-28 April, Amman, Jordan

7. Goldsworthy, A. and Rathore, K. S. (1985). The electrical control of growth in plant tissue cultures the polar transport of auxin. J. Exp. Bot. 36: $1134-1141$. 
8. Chand, P. K., O Chatt, S. J., Rech, E. L., Power, J. B. and Davey, M. R. (1988). Electroporation stimulate plant Regeneration from protoplasts of woods medical species Solanum dulcamara L. J. Exp. Bota. 39: 1267 - 1274.

9. AL-Mallah, M. K. and Salih, S. M. (2003). Electroporation increased growth of callus, regeneration capability and protein content of Solanum nigrum L. J. Plant Biology Special issues 14: 35 - 42.

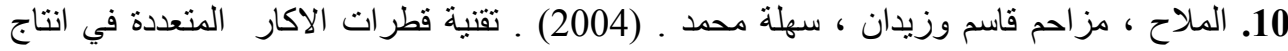

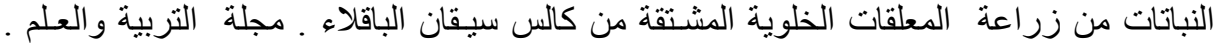

$$
\begin{aligned}
& \text { المجلد (16): العدد زعن } 2 .
\end{aligned}
$$

11. النزال ، فراس حميد. (2005) . استحداث وتمايز كالس القرنفل Dianthus caryophyllus مات أثثر المركبات الفينولية المستخلصة منه على فطريات الذيول الفيوزارمي ، رسالة

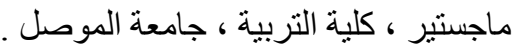

12. Murashige, T. and Skoog, F. ( 1962 ). A revised medium for rapid growth and bioassays with tobacco tissue culture. Physiol. Planta. 15: 473-497.

13. Davey, M. R. and Anthony, P. (2010). Plant Cell Culture, essential Tool.

14. Power, J. B., Davey, M. R., Mclellan, M. and Wilson, D. (1989). Laboratory Manual Plant Tissue Culture. PGMG Univ. Nottingham.

15. AL-Mallah, M. K. (2002). Invention of electroporation (AL - Jihad 1) and its applications in plant tissue culture. Patent System 3033. Office of Standardization and quality control.

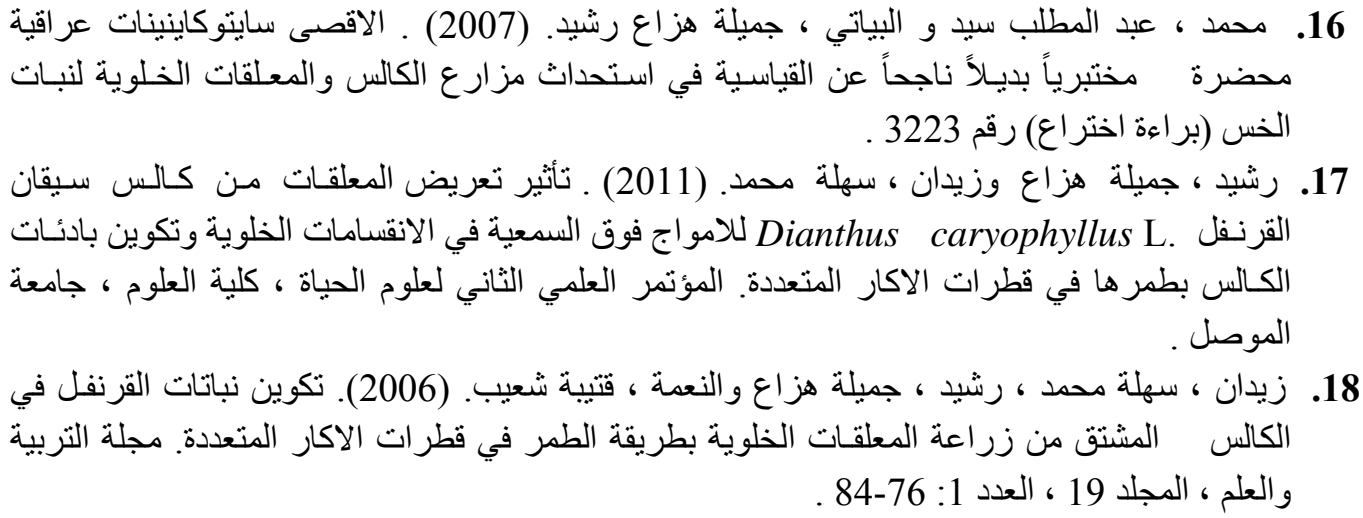

19. Ruffoni, B., Massabo, F. and Volpi, L. (1992). Suspension cultures of Dianthus caryophyllus cells. Acta Horticulture, 1(34).

20. Grosshoff, P. M. (1980). In vitro culture of white clover: callus, suspension protoplast culture, and plant regeneration. Bot. Goz. 141: 157-164.

21. Gupta, H. S., Rech, E. L., Cocking, E. C. and Davey, M. R. (1988). Electroporation and heat shock stimulate division of protoplasts of pennisetum squamulatum. Plant physiol. Vol. 133: 457- 459.

22. Hartman, H. T., Kaster, D. E., Davis, F. T. and Genever, R. L. (2002). Plant propagation principles and practices. Printice Hall. New Jersey, U. S. A. 